\title{
Has nature overwhelmed nurture?
}

\author{
There is a danger that too zealous and uncritical advocacy of the importance of human genome studies to the \\ exclusion of others may provoke disbelief, distrust and resentment.
}

THERE is a possibility that the most damaging pitfall in the path of the new genetics, and especially the Human Genome Project in its various manifestations, is none of the ethical questions so far raised, but the apparently inescapable triumphalism that accompanies major bursts of discovery. As new genes are found and linked with various of the human conditions by the study of family pedigrees in which those conditions are conspicuous, the general press is littered with news of the discovery of the gene 'for' this or that, haemophilia or even excessive aggression in males. One unexpected and unfortunate consequence is a growing belief in a kind of genetic predestination.

It is now literally 40 years since it became plain that inherited genes are not only the raw material for an organism's genetic endowment of its descendants, but that they also embody the biochemical programs by which cells of an organism conduct their business. That lesson seems generally to have sunk in, which is a triumph of a kind for the popularizers of science. The danger is that it may have sunk in too well, leaving people in general with the impression that not merely their physical well-being but also their behaviour is determined by the genes they happen to have inherited.

The implications of that proposition for the general conduct of human affairs are clearly profound. The possibility of predicting, with the help of appropriate genetic markers, that an individual will or will not contract one of several inheritable diseases on a quickly growing list thereof has already provoked fierce arguments (about health insurance and discriminatory employment, for example) which are not intrinsically novel, but which are likely to be increasingly clamant in the years ahead.

The Strong Genetic Principle, that every aspect of the human condition is predetermined by the genes, must inevitably raise more sound and fury. Will the time come when an abnormal nucleotide sequence is a sufficient defence in the courts against, say, a murder charge? When we know the gene 'for' kleptomania, will similar pleadings also set burglars free? Will what used to be moral philosophy and much of what is now called sociology be subsumed in the human genome projects? And how long will it be before the clever people in charge of those enterprises are able to predict, from a close examination of their sequences, the future of the novel as an art form?

These questions, put starkly in that form, will seem to many serious people to be so absurd as to deny the Strong Genetic Principle. But the confidence exuded by the genome projects leaves many others in doubt. And many who should know better have, sometimes in unguarded comments on their own discoveries, given comfort to genetic predestinarianism. But geneticists in particular, with the arguments about nature and nurture of the 1930s (on Hitler's Aryan concept) and 1960s (about the inheritance of IQ) fresh in their minds, should be more vividly aware than most that the Strong Genetic Principle is a fallacy.

Moreover, there is ample evidence, of a kind that will be as easily appreciated by the world at large as the doctrine of inherited DNA as a repository of inherited biochemical programs has been, to show that nurture still has a place in moulding the nature of an organism. There are many familiar proofs in the textbooks that a cell's DNA does not unambiguously determine its character.

On present understanding, for example, liver cells and lymphocytes from the same individual have identical complements of DNA, but very different properties. The present explanation is that different sets of genes are permanently activated in the lineages yielding the two different kinds of cells. The mathematicians would say that the relationship between DNA and phenotype is not necessarily single-valued. In the nematode and even Drosophila, the process of differentiation seems neatly hard-wired, although the molecular mechanisms that spell the differences between lineages have not yet been identified.

As it happens, the influences on undifferentiated cells that determine which lineage they follow are, in the strict sense, environmental, the secreted products of homeobox genes among them. Who at this stage can be sure that in more complicated (or less well studied) organisms, the same mechanisms may not allow for the moulding of the idiosyncrasies of an individual organism, perhaps even under environmental influences external to itself? In other words, there may ultimately be ample and even definable room for nurture.

The vivid textbook illustrations are the many accounts of how even organisms consisting of single cells can change their external form dramatically under different conditions. Some bacteria form viable spores when, for example, dehydrated, but their complement of DNA is not changed. Some yeast species even change their reproductive methods under environmental influences. That in utero influences can pro- foundly affect newborn babies (as in spina bifida, for example) is well documented. Is it likely that some of the most labile aspects of the human phenotype, those constituting personality, will be exempt from similar and more subtle influences?

What has been learned in recent decades about the plasticity of the newborn mammalian brain points directly to one point at which nurture must exert leverage. At least in the shaping of visual function, if the brain is a computer of a kind, its interconnections must be determined by experience of the uses to which this faculty will be put. Is not the same likely also to be true of other faculties, notably those constituting people's personality, whatever that may mean? And who will be surprised if the duration of plasticity, during which crucial interconnections are established, lasts longer than the few months characteristic of the visual system?

Classical genetics already provides latitude of this kind in the concept of the 'penetrance' of a gene. A recessively inherited condition such as sickle-cell anaemia can be unambiguously related to the underlying nucleotide sequences; two copies of the sickling globin gene generate red blood cells with the sickling habit and, as a consequence, the symptoms of anaemia. But the link between genotype and phenotype is not always unambiguous. A genotype may be a necessary, but not a sufficient, condition for the phenotype; the individual concerned inherits only a susceptibility for the phenotype. Penetrance is then simply the statistical chance that an individual inheriting the genotype in question will exhibit the associated phenotype. Of course, the strong genetic principle would be recovered if there were found to be other genes than those first identified that turn susceptibility into certainty, but (at this stage) it would be rash to deny that the missing ingredients may be aspects of nurture.

Especially in relation to human behaviour, it is possible to exclude the influence of nurture only by dismissing as unimportant a century of psychology and psychoanalysis. Although much of that may leave a lot to be desired by modern standards, it seems improbable that it can be entirely content-free. Most geneticists will probably agree that nurture still has a place. But to fail to say as much, explicitly, may generate more disbelief and even resentment than ethical worries have yet engendered. That would be a misfortune for a programme of such high promise.

John Maddox 